\section{As tramas do saber: ordenação dos sotaques e cânone científico}

Renato ORTIZ. A diversidade dos sotaques: o inglês e as ciências sociais. São Paulo, Brasiliense, 2008. 231 páginas.

\section{Maria Arminda do Nascimento Arruda}

No conto A biblioteca de babel, Jorge Luís Borges constrói a cena imaginária de uma infinita e interminável coleção de livros. Nenhum humano seria capaz de peregrinar por seus labirintos e nenhuma mente conseguiria compreender o seu ordenamento. Sempre haveria um livro a escapar, um corredor interminável, textos impenetráveis. Apesar de possuírem idênticos elementos, a variedade é de tal forma que "não há, na vasta Biblioteca, dois livros idênticos" (Borges, 1972a, p. 88). A Biblioteca de Babel é inacessível, a despeito das tentativas dos humanos de ordená-la, chegando ao limite de expurgá-la das obras consideradas inúteis ou impuras; toda intenção de dispô-la segundo um plano inteligível era derrotada diante da distância intransponível entre a sua infinitude e o caráter finito da vida. O conto borgiano representa, entre outros sentidos possíveis, uma alegoria da inapreensibilidade da existência e da diversidade da criação cultural. Por essa razão, talvez seja um bom ponto de partida para tratar do livro $A$ diversidade dos sotaques: o inglês e as ciências sociais, escrito pelo sociólogo Renato Ortiz.

À primeira vista é surpreendente que um sociólogo eleja como objeto de reflexão tema dessa natureza, principalmente nos anos atuais, após a relativização do linguistic turn e da crítica ao estruturalismo. A proposta, todavia, insere-se no âmbito dos estudos anteriores de Ortiz, dedicados à "modernidade-mundo", à mundialização da cultura do capitalismo, ou, segundo a acepção anglo-saxônica, da globalização. Nessa medida, o sociólogo retoma preocupações precedentes, ligadas ao entendimento dos processos sociais de homogeneização, de ultrapassagem das culturas nacionais, ao mesmo tempo da mescla cultural daí resultante, derivada da combinação de tecidos diversos. Longe de aderir às concepções norteadas por noções apaziguadas, baseadas no princípio da equivalência e do policentrismo global, o autor parte da posição hegemônica do inglês, a língua dominante da "modernidademundo", para retirar os efeitos desse domínio no curso da construção da ciência, especialmente das disciplinas sociais. Nesses termos, questiona a condição do seu próprio métier, os seus procedimentos usuais, o presente estádio das ciências sociais. "Ironicamente, no momento em que o mito da diversidade lingüística descola-se de sua versão bíblica, Babel, no âmbito da modernidade-mundo, uma língua adquire um sentido e uma posição hegemônica inquestionável. Isso possui inúmeras implicações, particularmente no domínio da ciência. Os que se dedicam a pensar as sociedades sabem disso, pois a língua é o instrumento através do qual se elabora o discurso escrito. Em que sentido ele não seria afetado pelo predomínio do inglês? Seria assim tão natural substituirmos nossos idiomas por outros, ou não haveria nesta operação ingênua um empobrecimento da própria reflexão?” (Ortiz, 2008, pp. 9-10).

Eis o problema central desse ensaio que irá percorrer toda a narrativa, e, ao mesmo tempo, será desfiado e ganhará corpo ao longo da própria escrita. Ou dito de outro modo, o autor não visa à demonstração, contrariamente busca conformar a própria questão no decorrer do texto, operando segundo um andamento crítico em que as idéias vão ganhando concretude ao serem retomadas num movimento em espiral. Daí, a sua característica de ensaio, pois além da forma referida, o sociólogo fala em nome próprio, uma vez que o seu discurso é autoral, afastando-se, pois, da pretensão da ciência em excluir o sujeito da locução. Ocorre, portanto, uma sincronia entre a feitura do texto e o problema a ser discutido, reforçando o traço autoral do livro, mas exprimindo, sobretudo, a relação estabelecida com a realidade da produção da ciência no nosso meio, questionando o senso comum e desnaturalizando concepções correntes. Por essa razão, a crítica empreendida é aparentada da consideração das ilusões difundidas na sociedade, não se separando do tratamento das ideologias, ainda que o seu substrato social seja difuso e tenha como suporte a comunidade dos cientistas e intelectuais que são formados, paradoxalmente, na cultura da negação do senso comum. Mas não é exatamente esse 
traço dissolvente e naturalizado da história que tipifica as ideologias? De acordo com essa perspectiva, $A$ diversidade dos sotaques é um livro inteligente porque persegue sentidos não imediatamente revelados, sendo mesmo erudito, haja vista a necessidade de ancorar os seus argumentos em volumosa e variada bibliografia.

Tendo como pano de fundo a formação da modernidade capitalista, Ortiz traceja os elementos fundacionais da cultura correspondente: racionalidade, logicidade, funcionalidade, praticidade, utilidade, simplicidade, facilidade, isto é, o conjunto de atributos homogeneizadores de um sistema dominado pela produção de mercadorias. Resulta, daí, a tendência a transformar todas as esferas da existência segundo os princípios dominantes, instaurando uma sorte de universalidade abstrata da qual a exigência do inglês como língua franca dos negócios e da política em âmbito internacional, assim como da ciência, passa a se confundir com o cosmopolitismo. No que se refere ao campo científico em especial, tem o papel de delimitar os critérios aceitos como os mais legítimos para o julgamento e para instituir as instâncias de reconhecimento. Diferencia-se, portanto, do significado que outrora teve o latim, uma vez que este se caracterizava por ser a língua dos doutos, apesar da sua condição de idioma morto, persistindo como uma forma exclusiva de comunicação entre pares; tampouco corresponde ao monolinguismo de raiz utópica, que grassou na Europa em diversos momentos.

A identificação do idioma inglês com todos esses princípios ordenadores do capitalismo é, no mundo contemporâneo, fenômeno repleto de significados, ao funcionar como se fosse puro sintoma da modernidade e do avanço civilizacional, como se fosse, em suma, expressão neutra da cultura. Operando, na verdade, como uma ideologia de segundo grau, por ser confundido como o idioma adequado da comunicação no decorrer de quase todo o século XX, encobre, sob o manto da neutralidade da língua, a hegemonia cultural e a dominação dos Estados Unidos no mundo, excluindo a particularidade das marcas sociais. Desse modo, Ortiz busca desmontar concepções a respeito da simplicidade e da praticidade da gramática inglesa, como se, ipso facto, tal característica, se é que ela se sustenta, seja a causa natural do uso da língua. "Pouco importa a veracidade dos fatos - no passado, idiomas 'difíceis' como o grego e o árabe conheceram uma expansão considerável. Inúmeras línguas adaptam as palavras estrangeiras para seu uso interno (fala-se, por exemplo, na bulimia do japonês). A argumentação se impõe pela sua evidência. Afinal, trata-se de provar o que já se sabe. O preconceito torna-se então superstição, e ao anunciarse cientificamente adquire uma solidez incontestável" (Idem, p. 54).

Ao inglês atribuiu-se, então, a condição de idioma despregado dos contextos sociais da sua produção, para cujo concurso a comunidade científica desempenhou papel central. A concepção da neutralidade lingüística adquire, assim, respaldo da ciência, similar à idéia de que a economia "é um domínio à parte, separado do mundo social, governado por leis naturais, universais, que os governos não devem contrariar" (Bourdieu, 2002, p. 26). Juntamente com o primado das leis naturais da economia, o inglês tornou-se um idioma da universalidade abstrata típica dos mecanismos do mercado, ambos nutridos da mesma unidade de medida que transforma o diverso em equivalente. A world language corresponde à era do neoliberalismo, da globalização, mesmo aos anos das especulações insensatas sobre o fim da história. O fenômeno da língua mundial não corresponde, todavia, à categoria de internacional, pois, segundo o autor, este pressupõe a persistência de unidades distintas, as nações, ao passo que o seu estatuto de "língua global" implica a passagem do forâneo em componente interno, impondo-se como se fosse autóctone (Ortiz, 2008, pp. 76-77). Tal reconversão nubla as formas de domínio cultural com a conseqüente exclusão de expressões que passam a ser vistas como defasadas, quando não inadequadas aos novos imperativos da comunicação, instaurando uma hierarquia entre as línguas, como se fossem dotadas de capacidades desiguais para representar o mundo. $\mathrm{O}$ inglês como "linguagem autorizada" oculta a relação de domínio simbólico dos falantes, a ponto de dispensar a compreensão efetiva do idioma, como ocorre com o fenômeno da chamada música internacional.

No que se refere à produção do conhecimento, o inglês converteu-se em língua da ciência, em 
requisito da internacionalização do saber, em exigência crescente das instituições e objetivo primacial dos agentes envolvidos. A internacionalização científica que só se realiza por intermédio da línguapadrão tornou-se a illusio da comunidade e do sistema da ciência contemporâneos, para incorporar a noção cunhada por Pierre Bourdieu. Assistimos, com isso, à transferência dos critérios de cientificidade das ciências naturais para as humanidades, que se caracterizam, precisamente, por organizar o pensamento na teia discursiva, por trabalhar com referências difusas que se concretizam no embate dos argumentos. Não por casualidade, são os poetas os principais inventores da língua e que é no ato da escrita que se corporifica a literatura, como bem revelou Roland Barthes (2004, pp. 4-5). A língua é a pátria dos poetas, para parafrasear a afirmação de Fernando Pessoa. Não há nenhuma garantia, nesse sentido, que o domínio de idiomas e a difusão da produção em contextos externos avalizem a relevância, o significado da reflexão e a profundidade do pensamento construído. Em outro conto de Borges, há uma passagem na qual o narrador observa: "Tinha aprendido sem esforço o inglês, o francês, o português, o latim. Suspeito, entretanto, que não era muito capaz de pensar" (Borges, 1972b, p. 124).

Enquanto a linguagem da literatura passa pelo crivo da criação, o idioma da ciência é pré-formado, estando tanto mais submetido às exigências correntes, quando se lhe aderem os requisitos de uma língua padrão. As diferenças entre disciplinas não são, pois, perfunctórias e nem acessórias, em função da diversidade do modo de construir o problema da pesquisa, em decorrência mesmo do caráter da arquitetura envolvida no estilo da produção do conhecimento. Essas distinções não autorizam, desse modo, que se atribua às disciplinas humanas $\mathrm{e}$ sociais a qualidade de desafinamento em relação ao saber da ciência. A dissonância existente deriva, antes, da particularidade da lógica na formulação dos problemas e da delimitação dos objetos, que se afasta das representações difundidas a respeito da correção científica e da norma imposta. A língua como criação social, por ser parte inextricável do tratamento do objeto considerado, é a portadora das categorias do pensamento. Tais categorias não são independentes das significações instituídas, uma vez que as imagens construídas são elas próprias reveladoras do mundo, segundo a lógica da filosofia de Wittgenstein, centrada nas questões da linguagem (cf. Wittgenstein, 1993, p. 16). Não é outro o motivo a garantir o caráter fundamental do idioma na constituição de distintos registros do conhecimento: por se prenderem às formas expressionais, isto é, aos meios de produção do conhecimento, as ciências humanas e sociais não lidam com contextos previamente construídos, uma vez que estes são internos aos objetos. "O idioma, as tradições intelectuais, as configurações bibliográficas, a interlocução, definem os sotaques da sua relevância" (Ortiz, 2008, p. 133). A particularidade dos contextos decorre, pois, do modo como se organiza a cultura em cada sociedade, animada por tradições intelectuais próprias e peculiares, orientando os procedimentos analíticos.

Já se disse que a recorrência do problema da formação histórica do Brasil distingue a tradição do pensamento brasileiro, como produto de certo mal-estar do intelectual cosmopolita na periferia moderna (cf. Arantes, 1997); também já se revelou o deslocamento do Brasil em face do sistema da ciência, como bem assinalou Roberto Schwarz a propósito da análise da literatura machadiana. Não há, portanto, como desconhecer a diversidade das tradições intelectuais; tampouco é possível admitir a independência dos pósteros em relação aos anteriores. Exatamente por esses motivos, o legado cultural de uma sociedade compreende o seu próprio idioma, que, embora não seja neutro, não pode ser alijado da modalidade de elaboração dos problemas do conhecimento, como mostra Jennifer Platt (2005) a partir de pesquisa voltada à análise da sociologia canadense.

Esse trânsito entre as referências locais e as exigências difundidas pelo cânone atual da ciência produz um cenário permeado de constrangimentos e hierarquias de vária ordem. A tradução de obras em idiomas de prestígio assegura aos autores posições superiores na escala das hierarquias vigentes. "Para os que padecem uma posição desfavorável, ela é imprescindível para a circulação das obras e para se acumular capital simbólico [...]. Esse tipo de situação favorece a existência de um conjunto hegemônico de representações mundializadas que 
passam a ser aceitas como válidas, naturalizando procedimentos metodológicos e problemáticas" (Ortiz, 2008, pp. 188-189, 200). A ilusão que identifica o idioma inglês ao universal compartilha do mesmo engano de julgar as ciências naturais como construtos em si mesmo neutros. Se as ciências sociais são um campo do conhecimento no qual não vigora a decantada distinção entre explicação e compreensão estabelecida por Wilhelm Dilthey, como certificou Pierre Bourdieu na afirmação de que nessas disciplinas "é preciso ser dito que compreender e explicar são a mesma coisa" (Bourdieu, 2003, p. 700), também nas disciplinas da natureza a formulação dos problemas de pesquisa não se desprende das questões do tempo, como atestam as transformações ocorridas no campo da biologia, em função tanto das mudanças culturais como da ampliação do recrutamento feminino nas carreiras antes predominantemente masculinas.

O complexo das questões enfrentadas pela obra elucida o quanto a reflexão é igualmente tributária dos problemas postos pela contemporaneidade do capitalismo global, desse estágio no qual a produção das mercadorias aprofundou o abismo existente entre os significados dos quais esses objetos são portadores e os seus referentes de origem. A presença dessas ilusões de segundo grau, por serem coletivamente compartilhadas, amplia a crença nas hierarquias entre as culturas, acaba por amesquinhar a maior parte das sociedades, relegando-as à condição de mensageiras de saberes inválidos. "A homologia postulada entre local-global, particular-universal, rebaixa as outras interpretações à posição subalterna de localismo. Convenientemente esquece-se de que o cosmopolitismo não é um atributo necessário da globalidade, e que o particularismo do pensamento enuncia-se tanto em dialeto, quanto em linguagem mundial, pois, na condição da modernidade-mundo, é perfeitamente plausível, e corriqueiro, ser globalmente provinciano" (Ortiz, 2008, p. 194). Com essas frases finais, Renato Ortiz arremata o texto segundo os postulados do ensaísmo crítico, inspirando-se na forma dominante de expressão intelectual entre nós; adere também, mesmo que possa não ter percebido, à interpretação de Antonio Candido a respeito da nossa cultura, quando afirma: "Se fosse possível estabelecer uma lei de evolução da nossa vida espiritual, poderíamos talvez dizer que toda ela se rege pela dialética do localismo e do cosmopolitismo, manifestada pelos modos mais diversos" (Candido, 1965, p. 131).

Exemplifica-se, dessa maneira, a relação inescapável entre as obras provenientes de uma determinada tradição intelectual, por estarem enleadas em problemáticas originadas em questões próprias aos diversos contextos. Independentemente da correção dos argumentos, não estaria a perspectiva crítica de Ortiz embebida da condição do intelectual na periferia, que é compungido a enfrentar em situação de desigualdade o sistema dominante? Não seria igualmente possível atribuir à dialética do localismo e do cosmopolitismo formulada por Antonio Candido a necessidade de referendar as conexões entre a vida intelectual brasileira e os centros avançados, construindo, por meio desse recurso, um lastro válido para o desenvolvimento da cultura no Brasil? Se essas questões aludem à presença de tradições intelectuais específicas, são, concomitantemente, reveladoras da formulação de problemas semelhantes, exprimindo a força de um legado intelectual que, ainda agora, inspira a maneira como problematizamos a nossa cultura, sintoma tanto da persistência de temas não superados como de uma forma assentada de reflexão.

Manifesta-se nessas afirmações a natureza da obra em análise: a despeito de tratar da língua, não se insere no bojo dos estudos aparentados da semiologia. O livro elabora uma crítica sociológica das próprias disciplinas sociais, ao discutir as instâncias de legitimação do conhecimento e da comunidade científica do tempo, que se desdobram no modo de produção das nossas ciências. A obra, no entanto, deixa de nomear os agentes que dão suporte a essa ordem de concepções, fazendo da disputa por posições mais reconhecidas um jogo entre participantes sem rosto, espécies de fantasmas nunca revelados. A nomeação, como se sabe, é condição das análises inspiradas na teoria dos campos de Pierre Bourdieu, como é requisito das interpretações sugeridas pela teoria das ideologias respaldadas nos sujeitos coletivos. Se a assimilação de tais procedimentos poderia enriquecer mais a análise, $A$ diversidade dos sotaques é obra criativa e original no panorama da sociologia brasileira, na medida em 
que enfrenta certezas inquestionáveis e visões há muito apascentadas por forças inescapáveis, que de tanto se afirmarem impuseram-se como uma segunda natureza, como se fossem o único caminho a levar em direção do universo da inteligência, como se houvesse um destino comum a todos.

Até por isso, talvez valha a pena retornar à Biblioteca borgiana e revisitar a expressão da agonia acompanhada de vago sentimento de esperança revelados nas frases do narrador. "Talvez a velhice e o medo enganem-me, mas suspeito que a espécie humana - a única - está por extinguir-se e que a Biblioteca permanecerá: iluminada, solitária, infinita, perfeitamente imóvel, armada de volumes preciosos, inútil, incorruptível, secreta... Minha solidão alegra-se com essa elegante esperança" (Borges, 1972a, p. 94).

\section{BIBLIOGRAFIA}

ARANTES, Paulo Eduardo. (1997), "Providências de um crítico literário na periferia do capitalismo”, in P. E. Arantes e O. B. F. Arantes, O sentido da formação, São Paulo, Paz e Terra.

BARTHES, Roland. (2004), "Da ciência à literatura", in , O rumor da lingua, São Paulo, Martins Fontes.

BORGES, Jorge Luís. (1972a) "A biblioteca de babel", in Ficções, São Paulo, Abril Cultural, pp. 84-94. . (1972b), "Funes, o memorioso", in , Fiç̧ões, São Paulo, Abril Cultural, pp. 115-125.

BOURDIEU, Pierre. (2002), Pierre Bourdieu entrevistado por Maria Andréa Loyola. Rio de Janeiro, Eduerj. . (2003), "Compreender", in Pierre Bourdieu (org.), A miséria do mundo. 5 ed. Petrópolis, Vozes.

CANDIDO, Antonio. (1965), "Literatura e cultura de 1900 a $1965 "$, in , Literatura e sociedade: estudos de teoria e história literária, São Paulo, Companhia Editora Nacional.

PLATT, Jeniffer. (2005), "La spécificité du Québec et du Canada dans les méthodologies en sociologie". Sociologie et sociétés, XXXVII (2).
SCHWARZ, Roberto. (1977), "As idéias fora do lugar", in , Ao vencedor as batatas, São Paulo, Livraria Duas Cidades.

WITTGENSTEIN, Ludwig. (1993), "A essência da proposição e a essência do mundo", in Luís Henrique Lopes dos Santos (org.), Introdução ao livro tratactus lógico-philosophicus, São Paulo, Edusp.

\section{MARIA ARMINDA DO NASCIMENTO ARRUDA é professora titular do Departamento de Sociologia da USP. E-mail: arr@usp.br}

